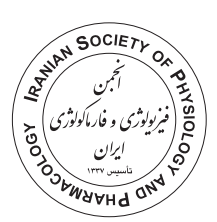

\title{
Evaluation of the effect of silver nanoparticles on OLN-93 oligodendroglial cells
}

\author{
Shabnam Nadjafi ${ }^{1}$, Roshanak Ghods ${ }^{2}$, Mehri Noori ${ }^{1}$, Vahid Pirhajati Mahabadi ${ }^{1}$, Nasrin Hosseini ${ }^{1 *}$ (iD)
}

1. Neuroscience Research Center, Iran University of Medical Sciences, Tehran, Iran

2. Research institution for Islamic and Complementary Medicine, Iran University of Medical Sciences, Tehran, Iran

\begin{abstract}
Introduction: Metals such as silver have special merit in medicine. Recently, it has been shown that silver nanoparticles (Ag-NPs) can present some properties that could be valuable for researchers because of their dual neuroprotective and neurotoxic behaviors. The present study was planned to evaluate the effect of silver nanoparticles on OLN-93 oligodendrocytes through chemical hypoxic situation.

Methods: AOLN-93 cell line was selected as an oligodendroglial cell model. The stock of the tested solution contained Ag-NPs with an average size of $40 \mathrm{~nm}$ and concentration of $20.4 \mathrm{ppm}$. Chemical hypoxic-ischemic condition was induced by sodium azide (NaN3). After a three-hour pretreatment of OLN-93 cells with Ag-NPs $(0.001 \mathrm{ppm})$, the cells were incubated in glucose-free medium with sodium azide $(100 \mathrm{mM}$ and $1 \mathrm{M})$ and Ag-NPs $(0.001 \mathrm{ppm})$ for $15 \mathrm{~min}$. Then, the reperfusion condition was set by returning the medium to DMEM with $10 \%$ FBS along with Ag-NPs $(0.001 \mathrm{ppm})$ for $24 \mathrm{~h}$. Next, the viability of the cells was assessed by MTT method. Also, Transmission electron microscopy images were used to evaluate the morphology of the cells.

Results: Our results showed that Ag-NPs with a concentration of 0.001 ppm could significantly increase ONL-93 cells survival through the $15 \mathrm{~min}$ hypoxic-ischemia condition induced by NaN3 $(100 \mathrm{mM})$ followed by reperfusion $(93.02 \pm 2.83)$. However, Ag-NPs $(0.001 \mathrm{ppm})$ could not protect the cells from hypoxic-ischemic injury induced by NaN3 (1M) through the same procedure.

Conclusion: Although the neurotoxic effects of Ag-NPs have been documented in many studies, the Ag-NPs solution, which was used in this study, could show protective effects on oligodendroglial cells in concentration of $0.001 \mathrm{ppm}$ during the planned model of chemical ischemia. Hence, more investigation is suggested to clarify the protective effect of Ag-NPs (average size of $40 \mathrm{~nm}$ ) on oligodendrocytes.
\end{abstract}

\section{Introduction}

Silver as a naturally occurring element has been used for medicinal purposes for thousands of years (Barillo

\author{
Keywords: \\ Oligodendrocytes \\ Silver nanoparticles \\ TEM
}

\footnotetext{
* Corresponding author: Nasrin Hosseini, hoseini.n@iums.ac.ir

Received 29 September 2020; Revised from 15 February 2021; Accepted 23 February 2021
}

Citation: Nadjafi S, Ghods R, Noori M, Pirhajati V, Hosseini N. Evaluation of the effect of silver nanoparticles on OLN-93 oligodendroglial cells. Physiology and Pharmacology 2021; 25: 363-372. http://dx.doi.org/10.52547/phypha.25.4.7 
usage of silver seems to be mentioned by Avicenna and Rhazuz (Honary et al., 2017). Nanomaterial is a natural, related, or synthetic material containing particles in an unbound state or as an aggregate or agglomerate in which $50 \%$ or more of the particles in number, size, distribution, or one or more external dimensions is in the size range of 1-100 $\mathrm{nm}$ (Shrestha and Kishen, 2016). Since the nanomaterials present exceptional physicochemical properties (e.g. ultrasmall sizes, large surface area/mass ratio and increased chemical reactivity) in comparison with their bulk counterparts (Shrestha and Kishen, 2016), these materials have recently been appeared as important players in modern medicine (Murthy, 2007). Nowadays, silver nanoparticles (Ag-NPs) have a widespread spectrum of applications ranging from disinfecting medical devices and home usage to water treatment and utilization in dentistry (Ahamed et al., 2010; Noronha et al., 2017). Moreover, Ag-NPs are important for their potential of application in the treatment of diseases that require maintenance of circulating drug concentration or targeting of specific cells or organs (Ahamed et al., 2010). Also, Ag-NPs are used to prevent and treat the infection of burns and open wounds (Khatoon et al., 2017; Thirumurugan et al., 2010).

In this regard, it is described that Ag-NPs have been detected in various brain regions (e. g. cerebral cortex, hippocampus) after prolonged oral exposure (Dąbrowska-Bouta et al., 2018; Skalska and Strużyńska, 2015). It is commonly reported that the repeated aggregation of Ag-NPs in the brain affects the neurological functions and induces neurotoxicity (Lebda et al., 2018). On the other hand, it is mentioned that herbal based synthesized nanoparticles are considered safer than their respective chemically synthesized equivalents (Khatoon et al., 2018). However, it is reported that small sphere of Ag-NPs with average-size of $35 \mathrm{~nm}$ can cause some neurotoxicity due to their interaction with acetylcholinesterase enzyme (Khatoon et al., 2018). Nevertheless, Gonzalez-Carter and colleagues for the first time in 2017 demonstrated a correlation between Ag-NP-detoxifying mechanisms and a reduction in microglial inflammation which serves a neuroprotective role.

It is known that the nervous system is constructed by two major cell types, including neurons and glial cells (Araque and Navarrete, 2010). Besides, glial cells are classified into different types with different functions: oligodendroglia, microglia, ependimoglia and astroglia
(Araque and Navarrete, 2010). In this regard, the oligodendrocytes are the myelinating cells that are necessary for the proper function of axons and oligodendrocytes damage results in injury to white matter that occurs in some neurologic diseases such as multiple sclerosis and psychiatric diseases (Giaume et al., 2007). According to the different reports about neurotoxic effects (Khatoon et al., 2018; Lebda et al., 2018) or neuroprotective role of Ag-NPs (Gonzalez-Carter et al., 2017), we intended to plan this study to evaluate the effects of an Ag-NPs solution on OLN-93 cells, the oligodendroglial cell line (Richter-Landsberg and Heinrich, 1996), through in vitro chemical induction of hypoxic-ischemic condition.

\section{Methods and materials}

Materials

The silver nanoparticles solution (SNB 110) used in this experiment were purchased from in house K.P Chem Company, Iran (Soheil Salmani, Mazeeyar Varasteh). The stock solution of Dulbecco's modified Eagle's medium (DMEM) was prepared (Sigma D5030). DMEM with glutamine, glucose/glutamine-free DMEM and fetal bovine serum (FBS) were purchased from GIBCO. Penicillin-streptomycin and 3-[4,5-Dimethylthiazol-2-yl]-2,5-diphenyl-tetrazolium bromide (MTT) were purchased from Sigma Chemical Co. (St. Louis, MO, USA). All other chemicals are of the purest grade existing from regular commercial sources.

Themorphology (size and stability of the nanoparticles) of Ag-NPs was determined by transmission electron microscopy (TEM) (LEO 906; 100KV; Zeiss, Germany) (Yin et al., 2013). TEM has also been applied to visualize the silver nanoparticles (Yin et al., 2013).

\section{Cell culture}

OLN-93 cell line, previously purchased from Pasteur Institute of Iran (Tehran, Iran), was gifted from the pharmacology department of Iran University of Medical Sciences. The cells were cultured in DMEM medium supplemented with $10 \% \mathrm{FBS}$ and $100 \mathrm{IU} / \mathrm{ml}$ penicillin and $100 \mu \mathrm{g} / \mathrm{ml}$ streptomycin in a humidified $95 \%$ air and $5 \% \mathrm{CO} 2$ incubator at $37{ }^{\circ} \mathrm{C}$ (Nadjafi et al., 2015). The cells were sub-cultured twice a week by gentle scraping and were cultured in a 96-well plate at a density of $5 \times 10^{4}$ cells $/ \mathrm{ml}$ and were used for experiments $24 \mathrm{~h}$ after seeding (Nadjafi et al., 2015). All experiments were approved by the Institute of Animal Care Committee at 
Iran University of Medical Sciences (code: IR.IUMS. REC.1397.659).

\section{Chemical hypoxic-ischemic assay}

Sodium azide $\left(\mathrm{NaN}_{3}\right)$, a well-known inhibitor of complex IV, is used to induce chemical hypoxia in vitro and in vivo (Ziabreva et al., 2010). Also, the reports indicate that the treatment of neuronal and oligodendroglial cell cultures with $\mathrm{NaN}_{3}$ can be employed to mimic some different pathological conditions of the nervous system (Selvatici et al., 2009; Ziabreva et al., 2010). In this regard, we used $\mathrm{NaN}_{3}$ to induce hypoxicischemic condition in OLN-93 oligodendroglial cells. The exposure of OLN-93 cells to $\mathrm{NaN}_{3}$ was planned based on the former studies (Ziabreva et al., 2010). In detail, in vitro ischemic condition was simulated by replacing the culture medium with glucose-free DMEM contained different concentrations of $\mathrm{NaN}_{3}$ $(10 \mathrm{mM}, 20 \mathrm{mM}, 50 \mathrm{mM}, 100 \mathrm{mM}, 1 \mathrm{M})$ for $15 \mathrm{~min}$ at $37^{\circ} \mathrm{C}$ under $5 \% \mathrm{CO}$. Sodium azide can produce a condition termed "chemical ischemia" which simulates the energy depletion occurring during ischemia (Marino et al., 2007). The effect of reperfusion was evaluated by exchanging the medium with fresh and complete DMEM with $10 \%$ FBS for $24 \mathrm{~h}$; then, the cell viability was tested by MTT assay. According to the results, two concentrations of $\mathrm{NaN}_{3}(100 \mathrm{mM}$ and $1 \mathrm{M})$ were selected to induce hypoxic-ischemic conditions in OLN-93 cells.

The procedure to evaluate the effect of $A g-N P S$ on OLN-93 cells

The procedure was planned similar to previous in vitro studies (Nadjafi et al., 2015). In detail, the OLN93 cells were pre-treated with Ag-NPs $(0.001 \mathrm{ppm})$ for three hours. The concentration of Ag-NPs (0.001ppm) was selected based on the concentration-response graph as shown in Figure 1a. Next, the cells were incubated in glucose-free medium with $\mathrm{NaN}_{3}(100 \mathrm{mM})$ and $\mathrm{Ag}$ NPs $(0.001 \mathrm{ppm})$ for $15 \mathrm{~min}$. Then, the cells were placed under reperfusion condition by using fresh and complete DMEM with $10 \%$ FBS along with Ag-NPs (0.001ppm) for $24 \mathrm{~h}$. Finally, the cells viability was assessed by MTT and data was presented based on the means of at least six measurements.

\section{Analysis of cell viability}

Oligodendroglial cell viability was measured by using the colorimetric MTT assay, as explained by Mosmann (1983). Briefly, cells were incubated with $0.5 \mathrm{mg} / \mathrm{ml}$ MTT in DMEM, at $37^{\circ} \mathrm{C}$ under $5 \% \mathrm{CO} 2$, for $3 \mathrm{~h}$. The blue formazan reduction product, produced by the action of succinate dehydrogenase on the dye in living cells, was dissolved in $100 \mu 1 \mathrm{DMSO}$. Then, the optical density was read at $570 \mathrm{~nm}$ using a Dynex MRX microplate reader (Dynex, Richfield, MN, USA). Data, which were determined based on the MTT reduction were presented as the percentage of viable cells in chemical hypoxicischemic-exposed columns of the plate compared with the control normoxic untreated columns (Nadjafi et al., 2015). The cells, which were only incubated with the culture media (DMEM along with 10\% FBS) through all the procedure were considered as control group with $100 \%$ viability.

Ultrastructural features of OLN-93 cells under TEM observation

The analysis of the ultrastructure changes of OLN-93 cells was performed by TEM study (Alamzadeh et al., 2019). In this regard, the effects of Ag-NPs on OLN93 cells after $\mathrm{NaN}_{3}$-induced hypoxic-ischemic condition and the following reperfusion were compared with untreated cells. Briefly, OLN-93 cells were collected by centrifugation. Next, the cells were washed with PBS and then cell fixation was performed in $2.5 \%$ glutaraldehyde for two hours. Afterwards, the cells were washed three times with PBS to remove free glutaraldehyde; then, post-fixation of the cells was accomplished in $1 \%$ osmium tetroxide for $1.5 \mathrm{~h}$. Next, the cells were dehydrated in acetone, infiltrated by resin and finally embedded in pure resin (Epon 812, TAAB, UK). Then, thin sections of samples $(50 \mathrm{~nm})$ were prepared and transferred on the 200-mesh uncoated grids and stained with uranyl acetate and lead citrate before imaging with TEM (LEO 906; 100KV; Zeiss, Germany) (Alamzadeh et al., 2019).

\section{Statistical analysis}

All data were recorded and analyzed using SPSS software version 22.0. All nominal data are expressed as mean \pm SEM. Statistical significance of differences throughout this study was assessed using one-way variance analysis (Tukey's test). A $P$-value of less than 0.05 was considered statistically significant. 

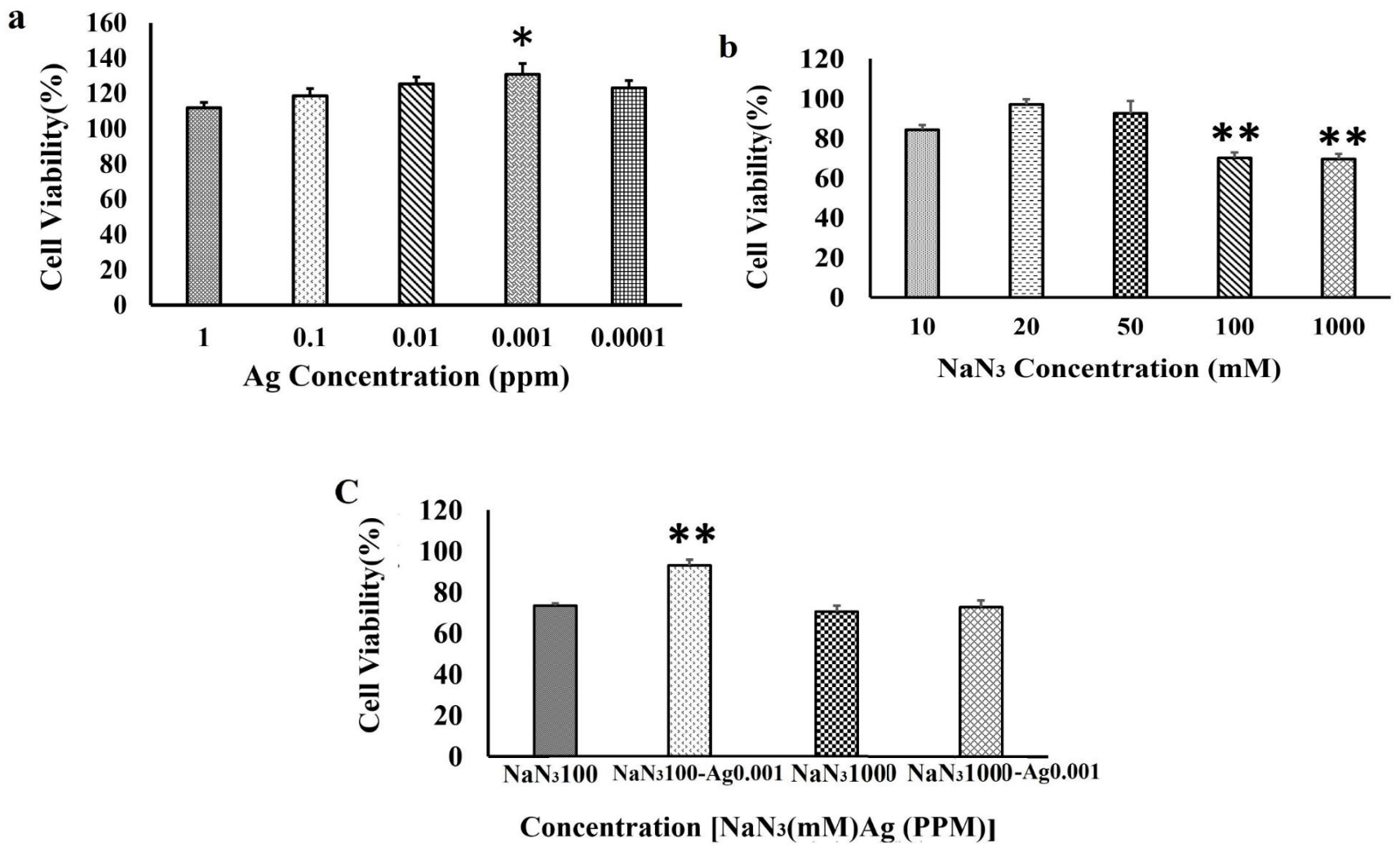

FIGURE 1. The concentration-response tests of Ag-NPs and $\mathrm{NaN}_{3}$ on OLN-93 oligodendrocytes and the effect of Ag-NPs on OLN-93 cell viability through $\mathrm{NaN}_{3}$-induced cytotoxic condition. In all the procedures (a-c), OLN-93 cells, which only treated with culture media (DMEM with $10 \%$ FBS), were considered as control group with $100 \%$ viability. (a) The effects of the several concentrations of Ag-NPs on OLN-93 cell viability. OLN-93 cells were treated with different concentrations of Ag-NPs, including 1, 0.1, 0.01, 0.001 or $0.0001 \mathrm{ppm}$, for $48 \mathrm{~h}$. Then, the cell viability was determined by MTT assay. Data are presented as mean \pm SEM. ${ }^{*} P<0.05$. (b) The effects of several concentrations of $\mathrm{NaN}_{3}$ on OLN-93 cell viability. OLN-93 cells were treated with different concentrations of $\mathrm{NaN}_{3}$, including 10, 20, 50, 100 and $1000 \mathrm{mM}$ for 15 min. Next, the cell viability was determined by MTT assay after $24 \mathrm{~h}$ reperfusion. Data are presented as mean \pm SEM. ${ }^{* *} P<0.01$. (c) The effects of Ag-NPs on OLN-93 cell viability through $\mathrm{NaN}_{3}$-induced cytotoxicity condition. OLN-93 cells were incubated with Ag-NPs (0.001ppm) for a three-hour pretreatment. Then, the cells were under chemical hypoxic condition by glucose-free medium with NaN3 (100 and $1000 \mathrm{mM})$ and Ag-NPs $(0.001 \mathrm{ppm})$ for $15 \mathrm{~min}$. Next, the cells placed under reperfusion condition by replacing the medium with fresh and complete DMEM with $10 \%$ FBS along with Ag-NPs $(0.001 \mathrm{ppm})$ for $24 \mathrm{~h}$. Finally, the cell viability was determined by MTT assay. Data are presented as mean \pm SEM. $* * P<0.01 . \mathrm{NaN}_{3}$, sodium azide; Ag-NPs, silver nanoparticles.

\section{Results}

Physical features of the silver nanoparticles and the solution

TEM was used to determine the characterizations of Ag-NPs and physical characteristics of the Ag-NPs is featured in Figure 2. The Ag-NPs were homogeneous and spherical in shape with average size $40 \mathrm{~nm}$. The concentration of $\mathrm{Ag}$ ions in the solution (20.4 ppm) was determined in the chemical analysis laboratory using of inductively coupled plasma optical emission spectrometry technique (Welna et al., 2020).

\section{$\mathrm{NaN}_{3}$ and $\mathrm{OLN}-93$ cell viability}

OLN-93 cells were incubated with several concentrations of $\mathrm{NaN}_{3}(10 \mathrm{mM}, 20 \mathrm{mM}, 50 \mathrm{mM}, 100 \mathrm{mM}$ and $1000 \mathrm{mM}$ ) for $15 \mathrm{~min}$. Then, the viability of OLN-93 cells was measured after a $24 \mathrm{~h}$-reperfusion by the colorimetric MTT assay. Further analysis demonstrated that maximum cell death was significant $(P<0.01)$ by $100 \mathrm{mM}$ and $1000 \mathrm{mM}$ concentrations of $\mathrm{NaN}_{3}$ in comparison with the other tested concentrations (Figure 1b). In detail, the OLN-93 cells viability after a $15 \mathrm{~min}$ chemical ischemic condition by $\mathrm{NaN}_{3}$ concentrations of 100 and $1000 \mathrm{mM}$ and a $24 \mathrm{~h}$ reperfusion were $74.31 \%$ and $69.62 \%$, respectively. Since there was not a significant statistical difference between the cell viabilities of the $\mathrm{NaN}_{3}$ concentrations of 100 and $1000 \mathrm{mM}$, both concentrations were used to induce chemical hypoxic-ischemic condition for assessment of Ag-NPs effect on OLN-93 cells.

Effect of Ag-NPs on OLN-93 cells in chemical hypox- 

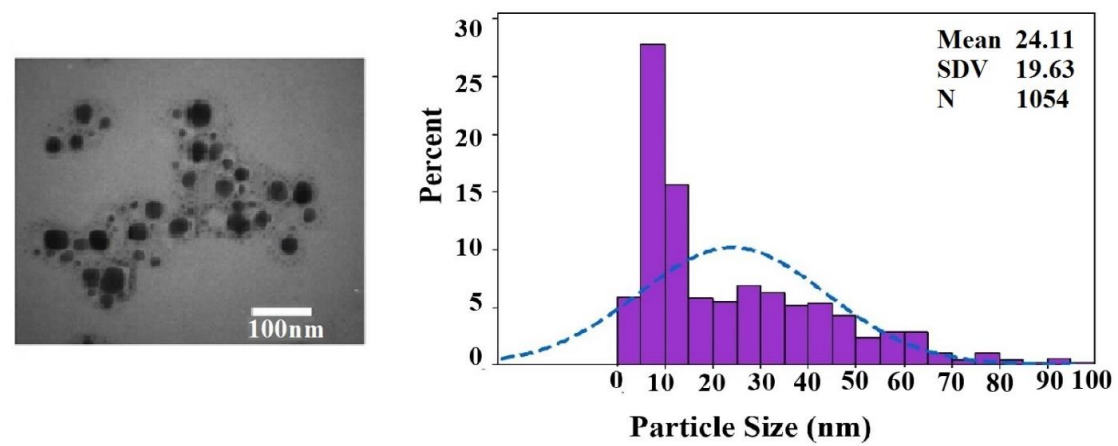

FIGURE 2. Transmission electron microscopy analysis of silver nanoparticles solution (SNB 110). (a) Representative micrograph showing Ag-NPs. (b) Histogram of Ag-NPs distribution.
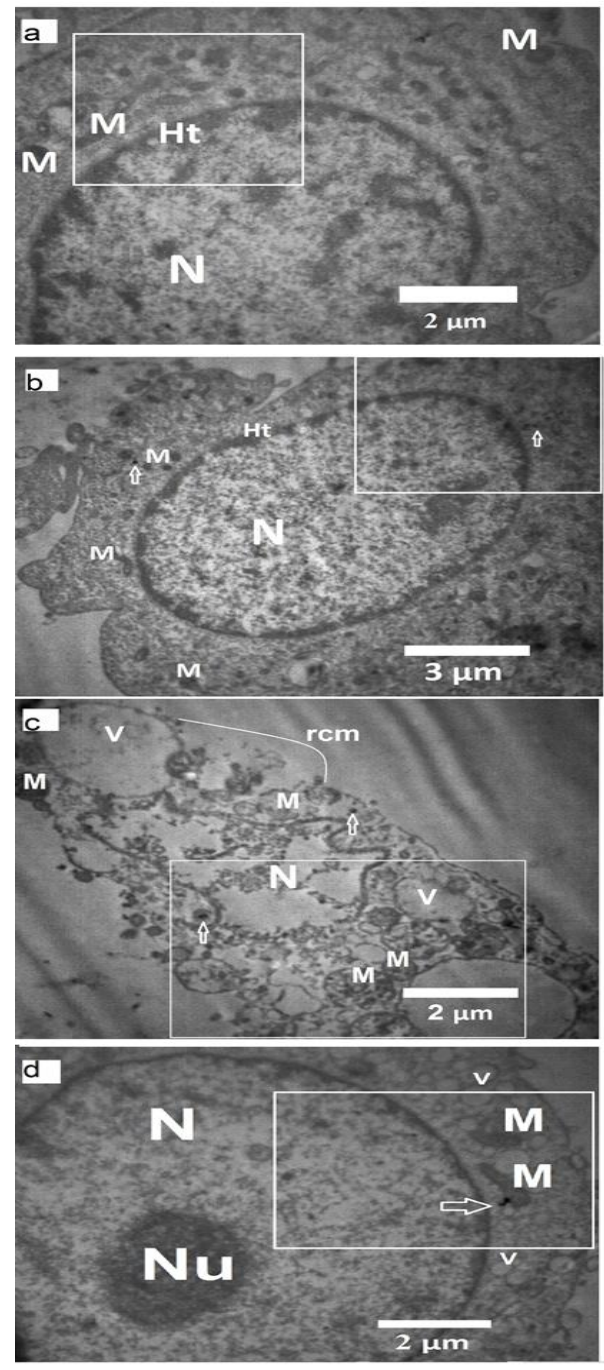
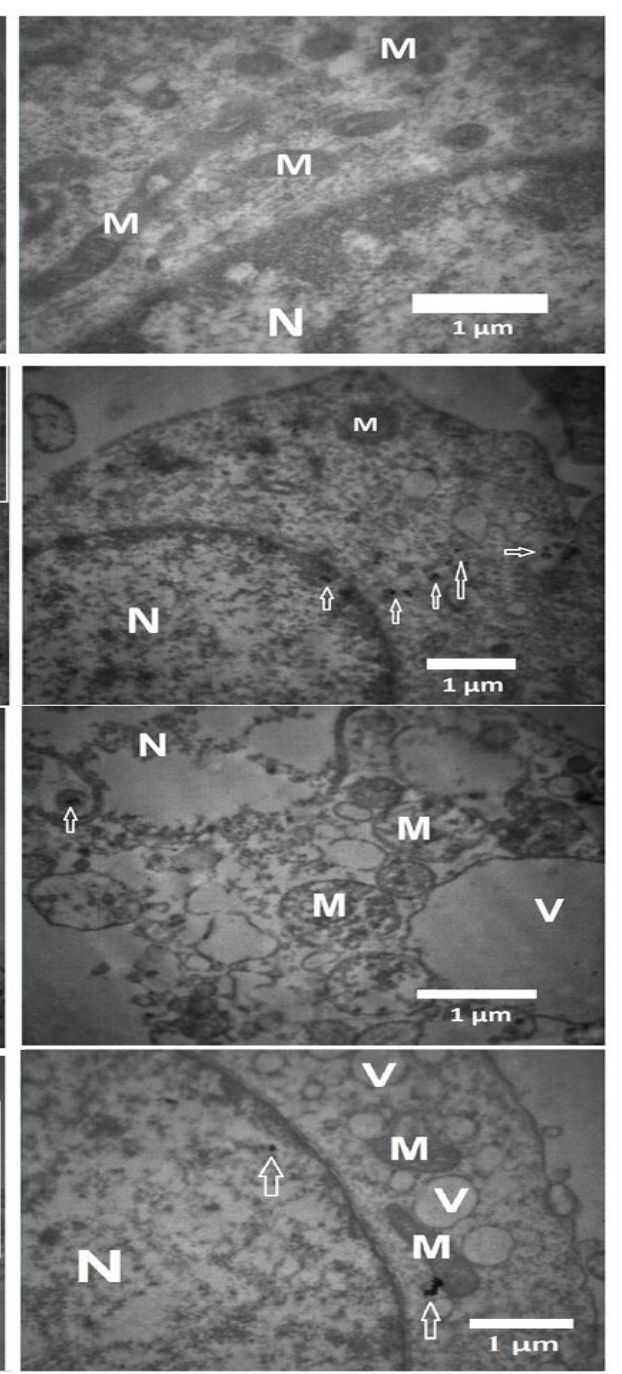

FIGURE 3. Ultrastructure of OLN-93 cells: (a) before any treatment; (b) after treatment with silver nanoparticles (Ag-NPs); (c) after treatment with sodium azide $\left(\mathrm{NaN}_{3}\right)$; (d) after pretreatment with Ag-NPs (0.001 ppm) for three hours followed by $\mathrm{NaN}_{3}(100 \mathrm{mM})$-induced chemical hypoxia in glucose-free medium along with Ag-NPs (0.001ppm) for $15 \mathrm{~min}$ and $24 \mathrm{~h}$ reperfusion condition by replacing the medium with fresh and complete DMEM with $10 \%$ FBS along with Ag-NPs (0.001 ppm). Arrows indicate the presence of silver nanoparticles or $\mathrm{NaN}_{3}$ in the OLN-93 cell. The abbreviations: rcm, Ht, V, M, N stand for rupture of cytoplasmic membrane, heterochromatin, vacuoles, mitochondria, nucleus, respectively.

\section{ic-ischemic condition}

Our results showed that Ag-NPs $(0.001 \mathrm{ppm})$ could significantly increase ONL-93 cell survival through $15 \mathrm{~min}$ $\mathrm{NaN}_{3}$ (100mM)-induced hypoxic-ischemia, followed by $24 \mathrm{~h}$ reperfusion, $(93.02535 \% \pm 2.832253, P<0.001)$. However, Ag-NPs $(0.001 \mathrm{ppm})$ could not protect the cells from $\mathrm{NaN}_{3}(1000 \mathrm{mM})$-induced hypoxic-ischemic injury through the same procedure (Figure 1c).

TEM observation and ultrastructural appearance of OLN-93 cells

Ultrastructure of OLN-93 cells was visualized by TEM assay to show the changes of the cells features after exposure to $\mathrm{NaN}_{3}$ and $\mathrm{Ag}$-NPs. Also, TEM was used 
to display the effects of Ag-NPs on $\mathrm{NaN}_{3}$-induced cytotoxicity. Figure 3a displays the photomicrograph of the control group of OLN-93 cells (no treatment) that the cell organelles such as mitochondria, heterochromatin and nucleus were shown. The photomicrograph of the OLN-93 cells in medium with Ag-NPs showed that the nanoparticles (Figure $3 \mathrm{~b}$ showed by arrow) can penetrate into the cells. Moreover, Figure $3 \mathrm{c}$ revealed the effects of $\mathrm{NaN}_{3}$ treatment on the cell structures. Accordingly, there was obvious presence of apoptosis related morphological features, which are mentioned in other cells and neurons, such as chromatin condensation, nuclear fragmentation, an increase in cell density and the formation of cytoplasmic blebs (Kalinichenko and Matveeva 2008). Furthermore, irregular shape and increased size of the nucleus (Kalinichenko and Matveeva 2008; Saraste and Pulkki 2000) and abnormal vacuoles (Kalinichenko and Matveeva 2008) were obscured. The pre-treatment and exposure of OLN-93 cells with AgNPs along with $\mathrm{NaN}_{3}$ resulted in protection against cell injuries wherein the structural morphologic alterations including interruption of plasma membrane, chromatin condensation, vacuoles damages, mitochondria abnormalities and nucleus membrane swelling were decreased. These features can be determined in the photomicrograph of the cells (Figure 3d).

\section{Discussion}

In this study, we evaluated the effects of an Ag-NPs solution (40nm diameters and $0.001 \mathrm{ppm}$ concentration) on OLN-93 oligodendroglial cells through $\mathrm{NaN}_{3}$-induced hypoxic-ischemic condition and the following reperfusion. The results of MTT assay revealed that treatment of OLN-93 cells by Ag-NPs (0.001 ppm) could protect the OLN-93 cells from cell demise during $\mathrm{NaN}_{3}(100 \mathrm{mM})$-induced hypoxic-ischemic condition. This result was in line with the findings from TEM that showed the entrance of Ag-NP to OLN-93 cells. AgNPs were appeared in OLN-93 cells and the main organelles such as nucleus and mitochondria had normal appearance similar to normal cells; however, these organelles severely damaged after solitary cell treatment with $\mathrm{NaN}_{3}$. Furthermore, Ag-NPs treatment could protect OLN-93 cells organelles from injury. It is known that vacuoles are common intracellular organelles and may occupy a significant part in the cells of plant, fungi and Protista (Shubin et al., 2016), but vacuoles are not usually existed in most animal cells as regular organelles (Shubin et al., 2016). However, cytoplasmic vacuolization of mammalian cells is defined as a morphological phenomenon that giant vacuoles are formed in animal cells in vivo and in culture (Shubin et al., 2016). It is important to know that the cytoplasmic vacuolization in animal cells may occur spontaneously or after exposure to bacterial or viral pathogens in addition to numerous natural and artificial low molecular-weight compounds (Shubin et al., 2016). On the other hand, the cytoplasmic vacuolization of mammalian cells can be transient or irreversible (Shubin et al., 2016) and irreversible vacuolization indicates cytopathological conditions that result cell death, as long as the cytotoxic stimulus is remained (Shubin et al., 2016). Also, mitochondria are vital organelles present in all eukaryotic cells including neurons and they not only have energy-generating function, but also participate in metabolism, calcium signaling, and apoptotic cell death (Sekine et al., 2003). Finally, nucleus is very dynamic organelle and contains the bulk of the genome and is involved in controls of all cell activities (Lamond and Earnshaw, 1998). According to the results of this study, it seems that Ag-NPs protection may proceed with anti-inflammatory effects via reduction of autophagic vacuoles and protection of mitochondrial systems against $\mathrm{NaN}_{3}$ toxicity in OLN-93 cells.

Since Ag-NPs presents remarkable broad-spectrum bactericidal properties and biocompatibility (i.e. as drug delivery agent), it makes Ag-NPs a really wide-range useful material (Bouallegui et al., 2017). In contrast, some studies reported the toxic effects of Ag-NPs such as neurovascular toxicity, astrocytes metabolic and biosynthesis suppression (Xu et al., 2015), voltage-gated sodium channels toxicity (Liu et al., 2009), as well as destructive effects on cortical cell survival through cytoskeletal and synaptic protein degradation, and mitochondrial degeneration in rats (Xu et al., 2013). By the way, the known mechanisms of neurotoxicity induced by Ag-NPs are specific to most nanoparticles, including the induction of oxidative stress, mitochondrial damage and an increase in the calcium levels related to transporter/receptor mechanisms (Teleanu et al., 2018).

In this regard, it is also important to know that neurotoxicity might be influenced by some characteristics of the Ag-NPs such as size, shape, surface coatings, rates of silver ions release and interactions with specific cells and proteins (Teleanu et al., 2018). Incidentally, a study 
on circulating immune cells in mytilus galloprovincialis, a marine invertebrate, notifies that nanotoxicity of Ag-NPs is size-dependent and indirectly dependent to duration of exposure (Bouallegui et al., 2017). Another case about the size-dependent effects of Ag-NPs indicates that Ag-NPs $(20 \mathrm{~nm})$ have high cytotoxic properties with respect to permeating and damaging cerebral microvascular structures, as compared with larger particles (40nm and $80 \mathrm{~nm}$ ) (Xu et al., 2013). In this regard, citrate-coated Ag-NPs (the average size: $19.8 \pm 2.1 \mathrm{~nm}$ ) can induce toxic effects on neurons and astrocytes, derived from human embryonic stem cells, because of mediating oxidative stress as the major cause of the neurotoxicity (Repar et al., 2018). Likewise, Ag-NPs with average size around $20-25 \mathrm{~nm}$ were used by Yin and colleagues and their findings notified that neurotoxic effect, resulted from Ag-NPs exposure, occurs via oxidative stress-induced apoptosis in rat cerebellum granule cells (Yin et al., 2013; Yin et al., 2015). Also, the neurotoxic potential of Ag-NPs (size: around 20nm) on rat motor dysfunction is associated with the reduction in expression of calcium channel protein (Yin et al., 2015). Moreover, it is stated that Ag-NPs with smaller sizes can show higher reactivity with biological membranes, more efficient cellular uptake and toxicity (Dąbrowska-Bouta et al., 2018).

However, it is mentioned that the effects of 20 and 40nm Ag-NPs on a mixed primary cell model containing mainly of neurons and astrocytes and a minor proportion of oligodendrocytes shows much more vulnerability of the astrocytes to Ag-NPs treatment in comparison with neurons (Haase et al., 2012). Therefore, it seems that the types of cells (e. g. neuron, astrocyte and oligodendrocyte) can also be important in evaluation the effects of 20 and 40nm Ag-NPs on the nervous system cell (Haase et al., 2012). Thus, it may need more focused tests to clarify the effect of the Ag-NPs on the different cell types of nervous system including oligodendrocytes. According to the findings, the size of Ag-NPs (40nm diameters), which were used in this study, was greater than the Ag-NPs, used by Yin and colleagues also Repar and colleagues (Repar et al., 2018; Yin et al., 2013; Yin et al., 2015). Then, it seems that the size of Ag-NPs (40nm diameters) could be considered as an effective factor in increasing survival of ONL-93 oligodendrocytes through the $\mathrm{NaN}_{3}(100 \mathrm{mM})$-induced hypoxic-ischemic and reperfusion experiment.
Another aspect about Ag-NPs-related toxicity could be the time exposure. For instance, prolonged low-dose exposure to Ag-NPs (size: $10 \pm 0.4 \mathrm{~nm}$ ) may result alteration in endothelial cells and may lead to the subsequent dysfunction of neurovascular unit (Dąbrowska-Bouta et al., 2018). Hence, it should be considered that the findings of this study, which showed that Ag-NPs $(0.001 \mathrm{ppm})$ could significantly increase ONL-93 oligodendrocytes survival, were resulted from a 15 -minute $\mathrm{NaN}_{3}(100 \mathrm{mM})$-induced hypoxic-ischemic challenge, followed by a 24-hour reperfusion time.

On the other hand, green synthesized Ag-NPs (spherical shape, size: $162.72 \pm 5.02 \mathrm{~nm}$ ), using aqueous extract of Pueraria tuberosa, presents in vitro anticancer activity in breast (MCF-7and MDA-MB-231), ovarian (SKOV3 ), brain (U-87) and multi-drug resistant (NCI/ADR) cancer cell lines (Satpathy et al., 2018). A similar study to ours revealed that green synthesize Ag-NPs (size: $565.1 \mathrm{~nm}$ with $100 \%$ intensity and width of $119.1 \mathrm{~nm}$ ) from stem of Nicotiana tabacum have in vitro antioxidant activity on rat PC-12 neuronal cells and results in neuroprotective effect against hydrogen peroxide-induced neurotoxic shock (Sharma, 2017). In addition, the synthetic Ag-NPs (spherical shapes with a mean size ranges between 12.86 to $28.19 \mathrm{~nm}$ ) from aqueous extracts of aerial parts of Lampranthus coccineus and Malephora lutea seems to be able to counteract oxidative stress and can be useful in treatment of Alzheimer's disease (Youssif et al., 2019). Furthermore, AgNPs with uniform, spheroid morphologies and a mean diameter of $49.7 \pm 10.5 \mathrm{~nm}$ reduces brain inflammation and related neurotoxicity through induction of hydrogen sulphide-synthesizing enzymes (Gonzalez-Carter et al., 2017).

\section{Conclusions}

In conclusion, the results of this in vitro study revealed that Ag-NPs (40nm diameters, $0.001 \mathrm{ppm}$ ) could significantly increase ONL-93 oligodendroglial cells survival through $15 \mathrm{~min} \mathrm{NaN}_{3}(100 \mathrm{mM})$-induced hypoxic-ischemic condition, followed by $24 \mathrm{~h}$ reperfusion; however, Ag-NPs $(0.001 \mathrm{ppm})$ could not protect the cells from $\mathrm{NaN}_{3}$ (1000mM)-induced hypoxic-ischemic injury during the same procedure. Obviously, the oligodendrocytes have the key role of myelination in the central nervous system and oligodenroglial injury is related to several neurologic diseases such as multiple sclerosis 
(Giaume et al., 2007) and the results of this study revealed the protective effect of Ag-NPs (40nm diameters, $0.001 \mathrm{ppm}$ ) on OLN-93 oligodenroglial cells in a model of chemical ischemic condition. Based on the previous aforementioned reports and the results of this study, it seems that the factors including the time exposure to Ag-NPs, the origin of the synthesis, size and shape of the Ag-NPs have critical roles to determine the toxic or protective effects of Ag-NPs on the oligodenrocytes and other cell types of the nervous system. Also, in vivo studies are suggested to clarify the toxic, protective or therapeutic effects of Ag-NPs on oligodendrocytes.

\section{Acknowledgment}

The authors would like to thank the Neuroscience Research Center collogues for their valuable assistance. This work was supported by Neuroscience Research Center, Iran University of Medical Sciences.

\section{Conflicts of interest}

none

\section{References}

Ahamed M, AlSalhi M S, Siddiqui M. Silver nanoparticle applications and human health. Clinica Chimica Acta 2010; 411: 1841-48. https://doi.org/10.1016/j.cca.2010.08.016

Alamzadeh Z, Beik J, Mahabadi V P, Ardekani A A, Ghader A, Kamrava S K, et al. Ultrastructural and optical characteristics of cancer cells treated by a nanotechnology based chemo-photothermal therapy method. J Photochem Photobiol B Biol 2019; 192: 19-25. https://doi.org/10.1016/j. jphotobiol.2019.01.005

Araque A, Navarrete M. Glial cells in neuronal network function. Philos Trans R Soc Lond B Biol Sci 2010; 365: 237581. https://doi.org/10.1098/rstb.2009.0313

Barillo DJ, Marx DE. Silver in medicine: a brief history BC 335 to present. Burns 2014; 40: S3-S8. https://doi. org/10.1016/j.burns.2014.09.009

Bouallegui Y, Ben Younes R, Turki F, Oueslati R. Impact of exposure time, particle size and uptake pathway on silver nanoparticle effects on circulating immune cells in mytilus galloprovincialis. J Immunotoxicol 2017; 14: 116-24. https://doi.org/10.1080/1547691X.2017.1335810

Dąbrowska-Bouta B, Sulkowski G, Frontczak-Baniewicz M, Skalska J, Sałek M, Orzelska-Górka J, et al. Ultrastructural and biochemical features of cerebral microvessels of adult rat subjected to a low dose of silver nanoparticles.
Toxicology 2018; 408: 31-8. https://doi.org/10.1016/j. tox.2018.06.009

Giaume C, KirchhoffF, Matute C, Reichenbach A, Verkhratsky A. Glia: the fulcrum of brain diseases. Cell Death Differ 2007; 14: 1324-35. https://doi.org/10.1038/sj.cdd.4402144 Gonzalez-Carter DA, Leo BF, Ruenraroengsak P, Chen S, Goode AE, Theodorou IG, et al. Silver nanoparticles reduce brain inflammation and related neurotoxicity through induction of H 2 S-synthesizing enzymes. Sci Rep 2017; 7: 42871. https://doi.org/10.1038/srep42871

Haase A, Rott S, Mantion A, Graf P, Plendl J, Thünemann A $\mathrm{F}$, et al. Effects of silver nanoparticles on primary mixed neural cell cultures: uptake, oxidative stress and acute calcium responses. Toxicol Sci 2012; 126: 457-68. https://doi. org/10.1093/toxsci/kfs003

Honary S, Dehshiri AM, Mosaddegh M. Fabrication and physicochemical investigation of ancient Iranian and Pakistani treated silver particles and their comparison with silver nanoparticles. Iran J Pharm Sci 2017; 16: 725-33.

Kalinichenko S, Matveeva NY. Morphological characteristics of apoptosis and its significance in neurogenesis. Neurosci Behav Physiol 2008; 38: 333-44. https://doi.org/10.1007/ s11055-008-0046-7

Khatoon A, Khan F, Ahmad N, Shaikh S, Rizvi S MD, Shakil $\mathrm{S}$, et al. Silver nanoparticles from leaf extract of Mentha piperita: eco-friendly synthesis and effect on acetylcholinesterase activity. Life Sci 2018; 209: 430-4. https://doi. org/10.1016/j.1fs.2018.08.046

Khatoon UT, Rao GN, Mohan KM, Ramanaviciene A, Ramanavicius A. Antibacterial and antifungal activity of silver nanospheres synthesized by tri-sodium citrate assisted chemical approach. Vacuum 2017; 146: 259-65. https://doi. org/10.1016/j.vacuum.2017.10.003

Lamond AI, Earnshaw WC. Structure and function in the nucleus. Science 1998; 280: 547-53. https://doi.org/10.1126/ science. 280.5363 .547

Lebda MA, Sadek KM, Tohamy HG, Abouzed TK, Shukry M, Umezawa M, et al. Potential role of $\alpha$-lipoic acid and Ginkgo biloba against silver nanoparticles-induced neuronal apoptosis and blood-brain barrier impairments in rats. Life Sci 2018; 212: 251-60. https://doi.org/10.1016/j. lfs.2018.10.011

Liu Z, Ren G, Zhang T, Yang Z. Action potential changes associated with the inhibitory effects on voltage-gated sodium current of hippocampal CA1 neurons by silver nanoparticles. Toxicology 2009; 264: 179-84. https://doi. org/10.1016/j.tox.2009.08.005 
Marino S, Marani L, Nazzaro C, Beani L, Siniscalchi A. Mechanisms of sodium azide-induced changes in intracellular calcium concentration in rat primary cortical neurons. Neurotoxicology 2007; 28: 622-29. https://doi. org/10.1016/j.neuro.2007.01.005

Mosmann T. Rapid colorimetric assay for cellular growth and survival: application to proliferation and cytotoxicity assays. J Immunol Methods 1983; 65: 55-63. https://doi. org/10.1016/0022-1759(83)90303-4

Murthy S K. Nanoparticles in modern medicine: state of the art and future challenges. Int J Nanomedicine 2007; 2: 129.

Nadjafi S, Ebrahimi S, Rahbar-Roshandel N. Noscapine protects OLN-93 oligodendrocytes from ischemia-reperfusion damage: Calcium and nitric oxide involvement. Acta Physiol Hung 2015; 102: 351-62. https://doi. org/10.1556/036.102.2015.4.2

Noronha VT, Paula AJ, Duran G, Galembeck A, Cogo-Mueller K, Franz-Montan M, et al. Silver nanoparticles in dentistry. Dent Mater 2017; 33: 1110-26. https://doi.org/10.1016/j. dental.2017.07.002

Repar N, Li H, Aguilar JS, Li Q Q, Drobne D, Hong Y. Silver nanoparticles induce neurotoxicity in a human embryonic stem cell-derived neuron and astrocyte network. Nanotoxicology 2018; 12: 104-16. https://doi.org/10.1080/1743539 0.2018 .1425497

Richter-Landsberg C, Heinrich M. OLN-93: A new permanent oligodendroglia cell line derived from primary rat brain glial cultures. J Neurosci Res 1996; 45: 161-73. https://doi. org/10.1002/(SICI)1097-4547(19960715)45:2<161::AID -JNR8>3.0.CO;2-8

Saraste A, Pulkki K. Morphologic and biochemical hallmarks of apoptosis. Cardiovasc Res 2000; 45: 528-37. https://doi. org/10.1016/S0008-6363(99)00384-3

Satpathy S, Patra A, Ahirwar B, Delwar Hussain M. Antioxidant and anticancer activities of green synthesized silver nanoparticles using aqueous extract of tubers of Pueraria tuberosa. Artif Cells Nanomed Biotechnol 2018; 46: S71-S85. https://doi.org/10.1080/21691401.2018.1489265

Sekine S, Miura M, Chihara T. Organelles in developing neurons: essential regulators of neuronal morphogenesis and function. Int J Plant Dev Biol 2003; 53: 19-27. https://doi. org/10.1387/ijdb.082618ss

Selvatici R, Previati M, Marino S, Marani L, Falzarano S, Lanzoni I, et al. Sodium azide induced neuronal damage in vitro: evidence for non-apoptotic cell death. Neurochem Res 2009; 34: 909-16. https://doi.org/10.1007/s11064-0089852-0
Sharma Y. Neuroprotective ability of tobacco stem silver nanoparticle on rat PC-12 cells. Asian J Pharm 2017; 11: 270-78.

Shrestha A, Kishen A. Antibacterial nanoparticles in endodontics: a review. J Endod 2016; 42: 1417-26. https://doi. org/10.1016/j.joen.2016.05.021

Shubin AV, Demidyuk IV, Komissarov AA, Rafieva LM, Kostrov SV. Cytoplasmic vacuolization in cell death and survival. Oncotarget 2016; 7: 55863. https://doi.org/10.18632/ oncotarget. 10150

Skalska J, Strużyńska L. Toxic effects of silver nanoparticles in mammals-does a risk of neurotoxicity exist. Folia Neuropathol 2015; 53: 281-300. https://doi.org/10.5114/ fn. 2015.56543

Teleanu DM, Chircov C, Grumezescu AM, Volceanov A, Teleanu RI. Impact of nanoparticles on brain health: An up to date overview. J Clin Med 2018; 7: 490. https://doi. org/10.3390/jcm 7120490

Thirumurugan A, Tomy N, Ganesh RJ, Gobikrishnan S. Biological reduction of silver nanoparticles using plant leaf extracts and its effect on increased antimicrobial activity against clinically isolated organism. Der Pharma Chemica 2010; 2: 279-84.

Welna M, Szymczycha-Madeja A, Pohl P. Simplified ICP OES-based method for determination of 12 elements in commercial bottled birch saps: validation and bioaccessibility study. Molecules 2020; 25: 1256. https://doi. org $/ 10.3390 /$ molecules 25051256

Xu F, Piett C, Farkas S, Qazzaz M, Syed NI. Silver nanoparticles (AgNPs) cause degeneration of cytoskeleton and disrupt synaptic machinery of cultured cortical neurons. Mol Brain 2013; 6: 29. https://doi.org/10.1186/1756-6606-6-29

Xu L, Dan M, Shao A, Cheng X, Zhang C, Yokel RA, et al. Silver nanoparticles induce tight junction disruption and astrocyte neurotoxicity in a rat blood-brain barrier primary triple coculture model. Int J Nanomedicine 2015; 10: 610518. https://doi.org/10.2147/IJN.S85265

Yin N, Liu Q, Liu J, He B, Cui L, Li Z, et al. Silver nanoparticle exposure attenuates the viability of rat cerebellum granule cells through apoptosis coupled to oxidative stress. Small 2013; 9: 1831-41. https://doi.org/10.1002/smll.201202732

Yin N, Zhang Y, Yun Z, Liu Q, Qu G, Zhou Q, et al. Silver nanoparticle exposure induces rat motor dysfunction through decrease in expression of calcium channel protein in cerebellum. Toxicol Lett 2015; 237: 112-20. https://doi. org/10.1016/j.toxlet.2015.06.007

Youssif KA, Haggag EG, Elshamy AM, Rabeh MA, Gabr 
NM, Seleem A, et al. Anti-Alzheimer potential, metabolomic profiling and molecular docking of green synthesized silver nanoparticles of Lampranthus coccineus and Malephora lutea aqueous extracts. PloS One 2019; 14: e0223781. https://doi.org/10.1371/journal.pone.0223781
Ziabreva I, Campbell G, Rist J, Zambonin J, Rorbach J, Wydro $\mathrm{M}$ M, et al. Injury and differentiation following inhibition of mitochondrial respiratory chain complex IV in rat oligodendrocytes. Glia 2010; 58: 1827-37. https://doi. org/10.1002/glia.21052 